\title{
BMJ Open What determines treatment satisfaction of patients with type 2 diabetes on insulin therapy? An observational study in eight European countries
}

\author{
Anne Meike Boels, ${ }^{1}$ Rimke C Vos, ${ }^{1}$ Tom G T Hermans, ${ }^{2}$ Nicolaas P A Zuithoff, ${ }^{1}$
} Nicolle Müller, ${ }^{3}$ Kamlesh Khunti, ${ }^{4}$ Guy E H M Rutten, ${ }^{1}$ GUIDANCE study group

To cite: Boels AM, Vos RC, Hermans TGT, et al. What determines treatment satisfaction of patients with type 2 diabetes on insulin therapy? An observational study in eight European countries. BMJ Open 2017;7:e016180. doi:10.1136/ bmjopen-2017-016180

- Prepublication history and additional material are available. To view these files please visit the journal online (http://dx.doi. org/10.1136/bmjopen-2017016180)

Received 31 January 2017

Revised 19 April 2017

Accepted 24 May 2017

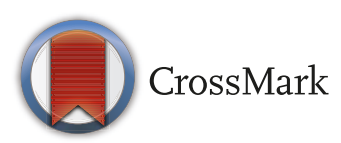

${ }^{1}$ Department of General Practice, Julius Center for Health Sciences and Primary Care, University Medical Center Utrecht, Utrecht, The Netherlands

${ }^{2}$ Faculty of Medicine, University Utrecht, Utrecht, The Netherlands

${ }^{3}$ Department of Internal Medicine III, University Medical Center, Jena, Germany

${ }^{4}$ Diabetes Research Centre, University of Leicester, Leicester, UK

Correspondence to Anne Meike Boels; a.m. boels-2@umcutrecht.nl, annemeikeboels@gmail.com

\section{ABSTRACT}

Objective Patients with type 2 diabetes (T2DM) on insulin therapy are less satisfied with their diabetes treatment than those on oral hypoglycaemic therapies or lifestyle advice only. Determinants of satisfaction in patients with T2DM on insulin therapy are not clearly known. The aim of this study was to determine the association of treatment satisfaction with demographic and clinical characteristics of patients with T2DM.

Design For this study we used data from the GUIDANCE (Guideline Adherence to Enhance Care) study, a crosssectional study among 7597 patients with T2DM patients from Belgium, France, Germany, Ireland, Italy, Sweden, the Netherlands and the UK. The majority of patients were recruited from primary care. Treatment satisfaction was assessed by the Diabetes Treatment Satisfaction Questionnaire (DTSQ, score 0-36; higher scores reflecting higher satisfaction). To determine which patient characteristics and laboratory values were independently associated with treatment satisfaction, a linear mixed model analysis was used.

Participants In total, 1984 patients on insulin were analysed; the number of included patients per country ranged from 166 (the Netherlands) to 384 (Italy).

Results The mean DTSQ score was $28.50 \pm 7.52$ and ranged from $25.93 \pm 6.57$ (France) to $30.11 \pm 5.09$ (the Netherlands). Higher DTSQ scores were associated with having received diabetes education $(\beta 1.64,95 \% \mathrm{Cl} 0.95$ to 2.32 ), presence of macrovascular complications ( $\beta 0.76$, $95 \% \mathrm{Cl} 0.21$ to 1.31$)$ and better health status $(\beta 0.08$ for every one unit increase on a $0-100$ scale, $95 \% \mathrm{Cl} 0.07$ to 0.10$)$. Lower DTSQ scores were associated with more frequently perceived hyperglycaemia $(\beta-0.32$ for every 1 unit increase on a seven-point Likert scale, $95 \% \mathrm{Cl}-0.50$ to -0.13$)$, and higher glycated haemoglobin ( $\beta-0.52$ for every percentage increase, $95 \% \mathrm{Cl}-0.75$ to -0.29 ). Conclusions A number of factors including diabetes education, perceived and actual hyperglycaemia and macrovascular complications are associated with treatment satisfaction. Self-management education programmes should incorporate these factors for ongoing support in patients with T2DM.

\section{Strengths and limitations of this study}

The large sample size of the study and participants from eight European countries with only a small percentage of missing data facilitate generalisability.

- The study was cross-sectional, hence no causality can be determined.

- The study relates to a group of patients with a relatively low treatment satisfaction and the results could potentially be applied in daily practice.

\section{INTRODUCTION}

As the global prevalence of type 2 diabetes mellitus (T2DM) is increasing, so is the number of patients with T2DM on insulin. Insulin is one of the oldest, most known and most effective agents in diabetes treatment. ${ }^{1}$ Timely initiation of insulin therapy to achieve adequate glycaemic control is often delayed because of patients' so-called 'psychological resistance' fuelled by misperceptions and myths; for physicians, beliefs about patient competence and risks are the main barriers to refrain from starting insulin therapy. ${ }^{23} \mathrm{But}$ even when insulin therapy is initiated, patients experience diabetes-related distress, ${ }^{4}$ they may view their injection regimen as highly burdensome, ${ }^{5}$ and not seldom they are less satisfied with their diabetes treatment than their counterparts. ${ }^{6-11}$ Against that background, one could argue that physicians are right in delaying insulin therapy. Indeed, patient satisfaction has been used as an indicator of quality of healthcare, which is important in chronic diseases like T2DM. ${ }^{812} 13$ To overcome patients' 'insulin resistance' and postponement of insulin therapy, it might be helpful if we know which factors contribute to treatment satisfaction in insulin-treated patients with T2DM. 
Several studies have investigated factors associated with diabetes treatment satisfaction. ${ }^{6-9} 111415$

Patients with T2DM with higher glycosylated haemoglobin (HbA1c) levels ${ }^{61114}$ and higher weight ${ }^{1114}$ were less satisfied, similar to those with diabetes complications. ${ }^{6-8} 15$ Women had lower scores on the Diabetes Treatment Satisfaction Questionnaire (DTSQ) compared with men. ${ }^{6}$ One study found that younger patients were less satisfied with their diabetes treatment, ${ }^{9}$ while two other studies found that older patients were less satisfied. ${ }^{71}$ Several other factors are associated with diabetes treatment satisfaction, for example, treatment in hospital, ${ }^{7}$ difficulties in taking medication ${ }^{8}$ and educational level. ${ }^{68}$ Only one study studied patients on insulin therapy separately: the authors performed a subgroup analysis restricted to insulin-treated patients in which they found that self-monitoring of blood glucose and self-management of insulin doses were associated with higher DTSQ scores, while no association for the number of insulin injections was found. ${ }^{6}$

None of the above-mentioned studies investigated solely patients with T2DM on insulin therapy. Therefore, our aim was to investigate factors associated with treatment satisfaction in patients with T2DM on insulin therapy. Knowing which factors contribute to treatment satisfaction would allow a tailored approach in clinical practice.

\section{METHODS}

\section{Study design}

For this study we used data from the GUIDANCE (Guideline Adherence to Enhance Care) study: a cross-sectional, observational study conducted from March 2009 to December 2010 in Belgium, France, Germany, Ireland, Italy, Sweden, the Netherlands and the UK to determine the quality of T2DM care. ${ }^{16}$ A more comprehensive description of the methods can be found in the article of Stone $e t a l^{16}$

\section{Study population}

The GUIDANCE study was a pragmatic observational study and included adult patients with T2DM from primary and secondary care with all diabetes therapies. Patients were excluded when they were pregnant, severely (mentally) ill, normally not managed by the recruiting physician or participated in a clinical trial with an intervention.

\section{Data collection}

The GUIDANCE database contains data from both physicians and patients. For the current study only data from patients on insulin therapy (all different regimens) were used, including data extracted from the medical records, and collected via three questionnaires: the Diabetes Treatment Satisfaction Questionnaire (DTSQ), the EuroQol Five Dimensions Questionnaire Visual Analogue Scale (EQ-5D-VAS) and a study-specific questionnaire. ${ }^{16-18}$

For the data extraction, a data collection form was developed to systematically collect data on demographics, anthropometric measurements, laboratory information, microvascular complications (abnormal foot sensation, presence of retinopathy or blindness and end-stage renal disease), macrovascular complications (amputation, peripheral arterial disease, ischaemic heart disease and stroke) and diabetes treatment. All extracted data were related to the 12 months prior to the date of recruitment. $^{16}$

The DTSQ covers eight items with regard to the diabetes treatment over the past weeks and measures overall satisfaction, convenience, flexibility, understanding of diabetes, willingness to recommend current treatment to others and willingness to continue the current treatment. Each item is rated on a 7-point Likert scale with a score ranging from 0 (ie, very dissatisfied) to 6 (ie, very satisfied). DTSQ items two and three assess glycaemic control rather than satisfaction (perceived hyperglycaemia and perceived hypoglycaemia). These items are rated differently: 0 reflects 'never' and 6 reflects 'most of the time'. All scores, except those from DTSQ items 2 and 3, are added up to produce a DTSQ total score (range 0-36). Higher scores on the DTSQ total score indicate higher treatment satisfaction and lower scores indicate lower treatment satisfaction. ${ }^{17}$

The EQ-5D-VAS assesses health status; it is a vertical line with a score ranging from 0 (worst health status) to 100 (best health status). Patients rate their health by marking a point on the line, corresponding with their perceived health status. ${ }^{18}$

Besides the two above-mentioned questionnaires, patients completed a study-specific questionnaire including questions on knowledge of diabetes, family history of diabetes, having ever received diabetes education, diabetes services and knowledge of guidelines. ${ }^{16}$

\section{Analyses}

Normal distributed data were reported by means and SD, non-normal distributed data were reported with medians and IQR, and categorical data were expressed as frequencies with percentages. Values for HbA1c were converted from NGSP (National Glycohemoglobin Standardization Program) units (\%) to IFCC (International Federation of Clinical Chemistry) units $(\mathrm{mmol} / \mathrm{mol}) .{ }^{19}$

Since the exclusion of patients with one or more missing values may reduce statistical power and may potentially lead to biased results, missing data were handled with multiple imputation. Insulin use was categorised into four groups: (1) basal insulin only, (2) mixed insulin two times per day, (3) a basal-bolus regimen or (4) other combinations. Per separate DTSQ item, a score of 4,5 or 6 was considered 'satisfied'. The factors associated with treatment satisfaction used in the analyses were either known from literature or based on clinical relevance. Based on literature, the association between DTSQ score and sex, age, country, diabetes duration, microvascular complications, macrovascular complications, depression, current smoking, diabetes education, health status, perceived hyperglycaemia (DTSQ item 2), perceived hypoglycaemia (DTSQ item 3), number of insulin injections daily, 
body mass index, HbA1c, fasting plasma glucose (FPG), low-density lipoprotein cholesterol and total cholesterol were investigated. ${ }^{6-121415}$ Based on clinical relevance, the association between DTSQ score, and systolic blood pressure and insulin regimen was additionally investigated. Treatment setting (primary or secondary care) was only included in the univariate analyses. We did not include treatment setting in the multivariate analyses because there was no statistically significant univariate association, and moreover because of the heterogeneity in healthcare organisation between the eight countries.

Because patients were included by physicians within a country, observations may be correlated and the data have a multilevel structure with three levels: countries-physicians-patients. To account for this hierarchical structure, we used a linear mixed model with random intercepts for country and physician. All other factors in the model, for example, age and HbAlc, were included as fixed effects. For both the univariate analyses and the multivariate analyses, DTSQ was included as the dependent continuous variable. Model assumptions were assessed with residual analyses. A $p$ value of $<0.05$ was considered statistically significant. Because we were specifically interested whether type of insulin regimen was associated with treatment satisfaction, we performed multiple multivariate linear mixed models to investigate the association between insulin regimen, and total DTSQ score and the separate DTSQ items.

We hypothesised that the association between total DTSQ score and having received diabetes education could be largely explained by the association between DTSQ item 6 ("how satisfied are you with your understanding of diabetes?") and having received diabetes education. To investigate the influence of DTSQ item 6, a sensitivity analysis was performed in which this DTSQ item was omitted from the total DTSQ score.

Statistical analyses were performed using IBM SPSS Statistics V.21 for Windows (SPSS, Chicago, Illinois, USA) and SAS V.9.4 (SAS, Cary, North Carolina, USA).

\section{RESULTS}

From the 7597 participants included in the GUIDANCE study, 1984 on insulin therapy were included in the current study. They were recruited from 316 physicians. In Sweden and the Netherlands, all patients were recruited from primary care, whereas in Italy only $3.9 \%$ of the patients were recruited from primary care (see online supplementary appendix 1). The number of included patients per country ranged from 166 (the Netherlands) to 384 (Italy) (table 1). Data on currently treated depression were missing not at random, namely for all Dutch participants $(n=166)$. Therefore, we did not impute the missing values for depression. In the total sample from the GUIDANCE study $(\mathrm{n}=7597)$, the mean DTSQ score was $28.88 \pm 5.77$ for those using insulin and $30.42 \pm 5.37$ for those not using insulin $(\mathrm{p}<0.001)$. In the separate database of patients on insulin, we imputed all
Table 1 Overview of the characteristics of the study population

\begin{tabular}{|c|c|}
\hline \multicolumn{2}{|l|}{ Factor } \\
\hline Age (years), mean $\pm S D$ & $66.8 \pm 11.0$ \\
\hline Sex: male, $n(\%)$ & $1070(53.9)$ \\
\hline Diabetes duration (years), median (IQR) & $12(10)$ \\
\hline Microvascular complications present, $\mathrm{n}(\%)$ & $865(43.6)$ \\
\hline Macrovascular complications present, $\mathrm{n}(\%)$ & $828(41.7)$ \\
\hline Smoking: current smoker, $\mathrm{n}(\%)$ & $261(13.2)$ \\
\hline Treated in primary care, $\mathrm{n}(\%)$ & $1202(60.6)$ \\
\hline \multicolumn{2}{|l|}{ Country, n (\%) } \\
\hline Belgium & $199(10.0)$ \\
\hline France & $176(8.9)$ \\
\hline Germany & $364(18.3)$ \\
\hline Ireland & $189(9.5)$ \\
\hline Italy & $384(19.4)$ \\
\hline The Netherlands & $166(8.4)$ \\
\hline Sweden & $206(10.4)$ \\
\hline UK & $300(15.1)$ \\
\hline Diabetes education received, $\mathrm{n}(\%)$ & $1498(75.5)$ \\
\hline Currently treated depression, $\mathrm{n}(\%)^{\star}$ & $179(11.3)$ \\
\hline Health status (EQ-5D-VAS), mean $\pm S D$ & $66 \pm 20$ \\
\hline DTSQ total score, mean \pm SD & $28.50 \pm 7.52$ \\
\hline DTSQ2: perceived hyperglycaemia, mean \pm SD & $2.64 \pm 1.85$ \\
\hline DTSQ3: perceived hypoglycaemia, mean $\pm S D$ & $1.55 \pm 1.91$ \\
\hline Body mass index $\left(\mathrm{kg} / \mathrm{m}^{2}\right)$, mean $\pm \mathrm{SD}$ & $31 \pm 6$ \\
\hline Systolic blood pressure $(\mathrm{mm} \mathrm{Hg})$, mean \pm SD & $137 \pm 17$ \\
\hline $\mathrm{HbA1c}(\%)$, mean $\pm \mathrm{SD}$ & $7.9 \pm 1.4$ \\
\hline $\mathrm{HbA1c}(\mathrm{mmol} / \mathrm{mol})$, mean $\pm \mathrm{SD}$ & $62.6 \pm 14.9$ \\
\hline Fasting plasma glucose (mmol/L), mean $\pm \mathrm{SD}$ & $8.5 \pm 3.7$ \\
\hline Cholesterol (mmol/L), mean \pm SD & $4.6 \pm 1.2$ \\
\hline LDL cholesterol (mmol/L), mean \pm SD & $2.5 \pm 0.9$ \\
\hline Injection frequency, median (IQR) & $2(3)$ \\
\hline \multicolumn{2}{|l|}{ Insulin regimen, $\mathrm{n}(\%)$} \\
\hline Basal & $603(30.4)$ \\
\hline Mix two times per day & $345(17.4)$ \\
\hline Basal-prandial & $709(35.7)$ \\
\hline Other & $327(16.5)$ \\
\hline
\end{tabular}

$n=1984$ for all factors except for 'currently treated depression'. ${ }^{*} \mathrm{n}=1768$.

DTSQ, Diabetes Treatment Satisfaction Questionnaire; EQ-5DVAS, EuroQol Five-Dimensions Questionnaire Visual Analogue Scale; HbA1c, glycated haemoglobin; LDL, low-density lipoprotein.

missing data. As a result, we counted DTSQ scores of people who did not have a score in the total sample data-

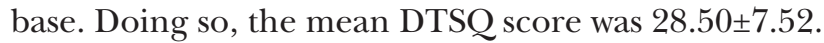

The mean age of the study population was $66.8( \pm 11)$ years, $53.9 \%$ were men and the median duration of T2DM was 12 (IQR 10) years. On average, the study population 
was reasonably well controlled, taking into account the duration of diabetes. The percentage of people with microvascular and macrovascular complications ranged between the countries from $24.1 \%$ (the Netherlands) to $51.3 \%$ (UK) and from $31.6 \%$ (Sweden) to $53.8 \%$ (Germany), respectively. With the exception of individuals from Italy, at least $70 \%$ of the participating patients reported having received diabetes education (see online supplementary appendix 1).

The mean DTSQ scores in our study population ranged from $25.93 \pm 6.57$ (France) to $30.11 \pm 5.09$ (the Netherlands) (see online supplementary appendix 1), resulting

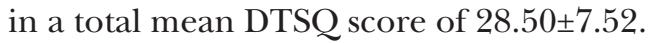

The proportion of patients who were satisfied for each component of the DTSQ items ranged from 79.8\% (DTSQ item 5 'flexibility') to $87.4 \%$ (DTSQ item 1 'overall satisfaction'). There was no difference between different insulin regimen groups with regard to the total DTSQ score and the scores on separate components of the DTSQ (table 2).

Table 3 demonstrates that patients who reported to have received diabetes education were more satisfied with their treatment $(\mathrm{p}<0.001)$, as were older patients $(\mathrm{p}=0.008)$, those with macrovascular complications $(\mathrm{p}=0.024)$ and those with a higher health status $(\mathrm{p}<0.001)$. Patients who were currently treated for depression $(p=0.007)$, those who frequently perceived hyperglycaemia $(p<0.001)$ and those with higher HbAlc levels $(p<0.001)$, FPG levels $(p<0.001)$ and cholesterol levels $(p=0.034)$ were less satisfied with their treatment.

The multivariate model shows that diabetes education, health status and presence of macrovascular complications were independently positively associated with higher treatment satisfaction, while perceived hyperglycaemia and HbAlc were independently negatively associated with treatment satisfaction (table 4). Residual analysis showed no deviation from distributional assumptions and no heteroscedasticity.

The sensitivity analysis, performed to investigate the influence of DTSQ item 'understanding of diabetes' on the association with diabetes education, still yielded in a statistically significant independent positive association between diabetes education and DTSQ scores, when this DTSQ item was omitted ( $\beta 1.23,95 \%$ CI 0.57 to 1.90 , $\mathrm{p}<0.001)$.

\section{DISCUSSION}

\section{Summary of main findings}

In 1984 patients with T2DM treated with insulin in eight European countries, we indeed found that patients on insulin therapy were less satisfied with their diabetes treatment than people who were treated with lifestyle only or with oral blood glucose-lowering agents. Those with a higher health status, macrovascular complications and who had received diabetes education were more satisfied with their diabetes treatment. Patients who frequently perceived hyperglycaemia and those

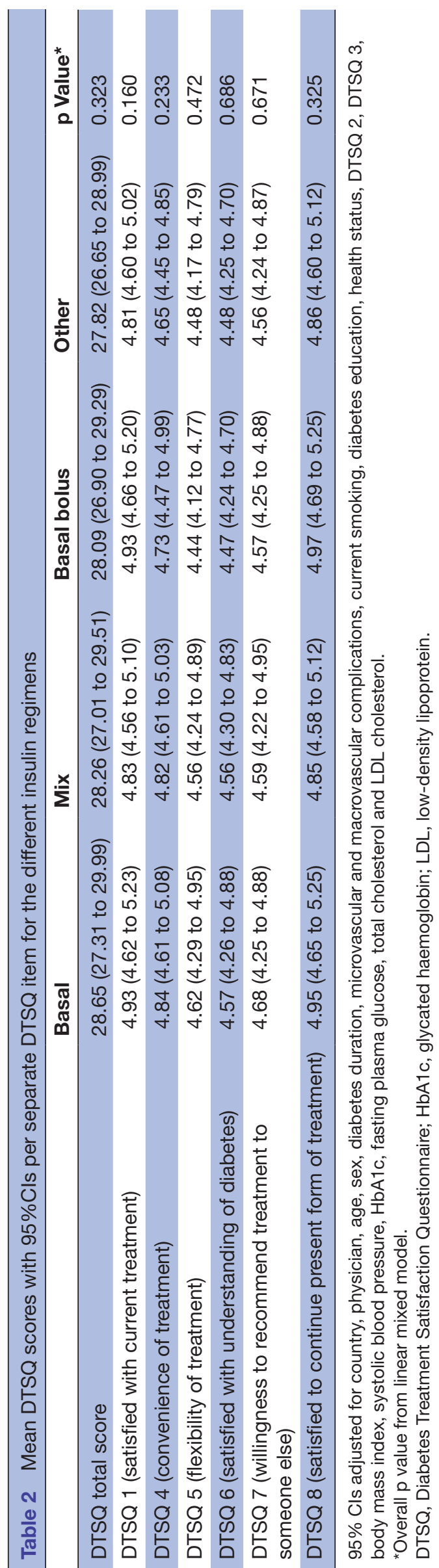


Table 3 Univariate linear mixed model for the association between treatment satisfaction and factors, adjusted for country and physician

\begin{tabular}{|c|c|c|c|}
\hline & $\beta$ & $95 \% \mathrm{Cl}$ & p Value \\
\hline Age (1 year increase) & 0.03 & 0.01 to 0.06 & 0.008 \\
\hline Sex & 0.16 & -0.37 to 0.70 & 0.545 \\
\hline Diabetes duration (1 year increase) & 0.02 & -0.02 to 0.05 & 0.305 \\
\hline Treatment setting & -0.92 & -2.11 to 0.26 & 0.127 \\
\hline Country* & & & $<0.001$ \\
\hline Belgium & -1.47 & -2.90 to -0.03 & 0.046 \\
\hline France & -3.20 & -4.67 to -1.74 & $<0.001$ \\
\hline Germany & 0.21 & -1.15 to 1.57 & 0.765 \\
\hline Ireland & -0.05 & -1.57 to 1.48 & 0.953 \\
\hline Italy & -1.76 & -3.47 to -0.05 & 0.043 \\
\hline The Netherlands & 0.95 & -0.66 to 2.55 & 0.248 \\
\hline Sweden & -0.06 & -1.52 to 1.40 & 0.932 \\
\hline UK & -ref. & -ref. & -ref. \\
\hline Currently treated depression ${ }^{\dagger}$ & -1.34 & -2.34 to -0.37 & 0.007 \\
\hline Microvascular complications & -0.27 & -0.84 to 0.31 & 0.359 \\
\hline Macrovascular complications & 0.62 & 0.08 to 1.17 & 0.024 \\
\hline Current smoking & -0.20 & -1.02 to 0.61 & 0.625 \\
\hline Diabetes education received & 1.65 & 0.93 to 2.37 & $<0.001$ \\
\hline Health status (EQ-5D-VAS) (1 unit increase $\left.{ }^{\ddagger}\right)$ & 0.09 & 0.08 to 0.11 & $<0.001$ \\
\hline DTSQ 2: perceived hyperglycaemia (1 unit increase ${ }^{\S}$ ) & -0.59 & -0.76 to -0.43 & $<0.001$ \\
\hline DTSQ 3: perceived hypoglycaemia (1 unit increase ${ }^{\S}$ ) & -0.32 & -0.67 to 0.03 & 0.068 \\
\hline Body mass index $\left(\mathrm{kg} / \mathrm{m}^{2}\right)$ (1 unit increase) & -0.03 & -0.07 to 0.02 & 0.276 \\
\hline Systolic blood pressure ( $\mathrm{mm} \mathrm{Hg}$ ) (1 unit increase) & -0.01 & -0.02 to 0.01 & 0.356 \\
\hline HbA1c (\%) (1 unit increase) & -0.80 & -1.00 to -0.61 & $<0.001$ \\
\hline $\mathrm{HbA} 1 \mathrm{c}(\mathrm{mmol} / \mathrm{mol})$ (1 unit increase) & -0.07 & -0.09 to -0.06 & $<0.001$ \\
\hline Fasting plasma glucose (mmol/L) (1 unit increase) & -0.31 & -0.44 to -0.17 & $<0.001$ \\
\hline Total cholesterol (mmol/L) (1 unit increase) & -0.27 & -0.53 to -0.02 & 0.034 \\
\hline LDL cholesterol (mmol/L) (1 unit increase) & -0.19 & -0.52 to 0.13 & 0.238 \\
\hline Injection frequency (1 unit increase ") & -0.10 & -0.38 to 0.18 & 0.482 \\
\hline
\end{tabular}

Reference categories: sex = women; treatment setting = primary care; currently treated depression = no, microvascular complications = no; macrovascular complications $=$ no; current smoking $=$ no; diabetes education $=$ no.

${ }^{*}$ Only adjusted for physician. $\nmid n=1768 . \neq O n$ a 0-100 scale.§On a seven-point Likert scale. \|On a five-point Likert scale.

$\beta$, regression coefficient; DTSQ, Diabetes Treatment Satisfaction Questionnaire; EQ-5D-VAS, EuroQol Five Dimensions Questionnaire Visual Analogue Scale; HbA1c, glycated haemoglobin; ref., reference category.

with higher HbA1c levels were less satisfied. No association was found between treatment satisfaction and insulin regimen, nor between treatment satisfaction and insulin injection frequency.

While the current study has a large sample size with only a small percentage of missing data, some limitations should be considered. First, the factors included in our model only explained small differences in DTSQ score (maximum $\beta 1.64$ for diabetes education). So, while diabetes education, macrovascular complications, health status, perceived hyperglycaemia, and HbAlc levels are important factors in treatment satisfaction, there are many other unmeasured factors not examined in this study. These may be factors similar to those that are associated with psychological insulin resistance such as health beliefs and feelings of failure. ${ }^{2}$ Second, since the study was cross-sectional, no causality can be determined, though one can speculate about the direction of the effects. For some of our findings, the direction of the effect can be both ways, for example, for HbAlc, poor metabolic control may lead to low treatment satisfaction, but low treatment satisfaction may also lead to poor metabolic control. However, the aim of the current study was not to investigate causality, but to explore which factors could be associated with treatment satisfaction. Third, the univariate analyses showed an association between 
Table 4 Multivariate linear mixed model for the independent association between treatment satisfaction and factors $(n=1984)$

\begin{tabular}{|c|c|c|c|}
\hline Factor & $\boldsymbol{\beta}$ & $95 \% \mathrm{Cl}$ & p Value \\
\hline Age (1 year increase) & 0.02 & -0.01 to 0.05 & 0.181 \\
\hline Sex & -0.33 & -0.85 to 0.19 & 0.212 \\
\hline Microvascular complications & -0.22 & -0.77 to 0.32 & 0.426 \\
\hline Macrovascular complications & 0.76 & 0.21 to 1.31 & 0.007 \\
\hline Diabetes education & 1.64 & 0.95 to 2.32 & $<0.001$ \\
\hline Health status (EQ-5D-VAS) (1 unit increase*) & 0.08 & 0.07 to 0.10 & $<0.001$ \\
\hline DTSQ2: perceived hyperglycaemia (1 unit increase + ) & -0.32 & -0.50 to -0.13 & 0.001 \\
\hline DTSQ3: perceived hypoglycaemia (1 unit increase†) & -0.24 & -0.61 to 0.13 & 0.176 \\
\hline Body mass index $\left(\mathrm{kg} / \mathrm{m}^{2}\right)$ (1 unit increase) & 0.03 & -0.02 to 0.08 & 0.181 \\
\hline $\mathrm{HbA} 1 \mathrm{c}(\mathrm{mmol} / \mathrm{mol})$ (1 unit increase) & -0.05 & -0.07 to -0.03 & $<0.001$ \\
\hline Fasting plasma glucose (mmol/L) (1 unit increase) & -0.09 & -0.24 to 0.06 & 0.214 \\
\hline Total cholesterol (mmol/L) (1 unit increase) & -0.13 & -0.52 to 0.26 & 0.513 \\
\hline LDL cholesterol (mmol/L) (1 unit increase) & 0.19 & -0.31 to 0.69 & 0.448 \\
\hline Injection frequency (1 unit increase $\neq$ ) & 0.24 & -0.36 to 0.84 & 0.401 \\
\hline
\end{tabular}

Reference categories: $\mathrm{sex}=$ women; microvascular complications = no; macrovascular complications = no; smoking = no; diabetes education $=$ no.

${ }^{*}$ On a $0-100$ scale.

†On a seven-point Likert scale.

$\ddagger$ On a five-point Likert scale.

$\beta$, regression coefficient; DTSQ, Diabetes Treatment Satisfaction Questionnaire; EQ-5D-VAS, EuroQol Five Dimensions Questionnaire Visual Analogue Scale; FPG, fasting plasma glucose; HbA1c, glycated haemoglobin; LDL, low-density lipoprotein; ref., reference category; SBP, systolic blood pressure.

being treated for depression and treatment satisfaction. Unfortunately, because we could not impute the missing data for depression in a valid way, we were not able to take depression into account in the multivariate analysis. Lastly, data on duration of insulin treatment were not available, which might have been influential, as previous research showed that the burden of insulin treatment is reduced by experience. 5

\section{Comparison with existing literature}

Only one other study investigated treatment satisfaction in patients with T2DM treated with insulin therapy (in a subgroup analysis). ${ }^{6}$ All other studies investigated patients with T2DM treated with all diabetes therapies, ${ }^{6-12} 15$ or with oral hypoglycaemic agents only. ${ }^{14}$

Our finding, that higher HbAlc levels were associated with lower treatment satisfaction, is in line with the results of other studies. ${ }^{61114}$ Similar to our results, Nicolucci et al found that general health perception score, measured with the Short Form (36) Health Survey, and DTSQ scores were positively correlated; we found a positive correlation between health status measured with the EQ-5D-VAS and DTSQ score. ${ }^{6}$ Finally, we did not find an association between DTSQ score and insulin regimen and insulin injection frequency. This is in concordance with the findings of Nicolucci et al, who too were not able to demonstrate an association between DTSQ score and the number of insulin injections. ${ }^{6}$

Bener et al did not find a statistically significant difference in DTSQ scores between patients who had received diabetes education, and those who had not. ${ }^{7}$ Unfortunately, the authors did not provide information on how data on diabetes education was collected (eg, whether or not it was patient-reported) and did not specify which type of diabetes they studied. This makes it hard to speculate about the difference in findings, and moreover, cultural background and organisation of care in Qatar may also be a unique factor.

We found an inverse relationship between perceived hyperglycaemia and DTSQ score: the more frequently perceived hyperglycaemia, the lower the treatment satisfaction. For perceived hypoglycaemia no statistically significant association was found. Interestingly, while Nicolucci et al too found that perceived hyperglycaemia was negatively associated with treatment satisfaction, they found that perceived hypoglycaemia was positively associated with treatment satisfaction. ${ }^{6}$ They hypothesise that this might be the case because patients accept to "pay the price' (ie, hypoglycaemia) to achieve good glycaemic 
control. Perhaps the difference with our results is due to the fact that we studied patients on insulin therapy only. These patients may be highly focused on preventing hypoglycaemic events. Therefore, we hypothesise that some patients will perceive a hypoglycaemic event as a failure of their insulin therapy (which may lead to lower treatment satisfaction), while others might perceive a hypoglycaemic event as something that is inevitable when trying to achieve adequate glycaemic control. As a more or less balanced result, perceived hypoglycaemic events will not have influenced mean treatment satisfaction in our sample of insulin-treated patients.

Patients with macrovascular complications were more satisfied with their treatment, in contrast to other studies, where having any diabetes complication versus none was associated with lower treatment satisfaction. ${ }^{7815}$ This discrepancy may be explained by differences in definitions: for example, Bener $e t a l$ and Biderman $e t$ al defined any diabetes complication as retinopathy, nephropathy and/or foot ulcer; they did not take macrovascular complications other than foot ulcer into account.

\section{Interpretation of results}

Of all the specific DTSQ items, the item about flexibility was rated lowest. Indeed, patients on insulin therapy are less flexible with regard to their diet and physical activity, but fortunately the mean scores on this item did not differ between the different insulin regimens. Still, almost $80 \%$ of the patients found their treatment flexible, which we think is a reassuring proportion on the one hand, but emphasises the need for improvement: one in five could improve. To increase satisfaction in this respect, omitting the injection-to-meal interval inpatients with T2DM with flexible insulin therapy should also be considered. ${ }^{20}$ We did not find an association between treatment satisfaction and insulin regimen or injection frequency. It might be possible that the negative aspects of a more intensive insulin regimen (ie, higher insulin injection frequency), are counterbalanced by other positive aspects such as increased flexibility and better diabetes control. Interestingly, studies on type 1 diabetes mellitus found that patients with continuous subcutaneous insulin infusion (CSII) were more satisfied with their treatment compared with those on multiple daily injections. ${ }^{21} 22$ One observational study even found a difference of 4 points in DTSQ score after adjustment for age, sex and diabetes duration. ${ }^{21}$ When CSII will become more ubiquitous, it would be interesting to investigate this in T2DM too.

Patients who have received diabetes education were more satisfied than those who did not. Even when the DTSQ item 'understanding of diabetes' was omitted, a statistically significant positive association between diabetes education and treatment satisfaction remained. This suggests that diabetes education is more than solely the transmission of knowledge; it is also about providing patients with the ability and skills that are necessary for proper diabetes management. ${ }^{23}$ Regardless of the underlying mechanism, this finding stresses the importance of diabetes education for all patients on insulin therapy.

Both perceived hyperglycaemia and HbAlc level were independently positively associated with treatment satisfaction. These findings point to the fact that physicians should carefully communicate with their patients about HbA1c levels. Moreover, applying individualised glycaemic targets might additionally improve treatment satisfaction for individuals with less strict targets. ${ }^{24}$

Patients with macrovascular complications were more satisfied with their treatment compared with those without macrovascular complications. This might be because healthcare providers are more attentive to patients with a macrovascular complication, which can lead to higher treatment satisfaction. This is supported by the finding of an earlier study, where researchers found that patients with incident diabetes-related comorbidity were more intensively treated. ${ }^{25}$

The difference in satisfaction between the eight countries was only investigated in the univariate analyses. The differences found here may be caused by differences in organisation of care and cultural differences.

\section{CONCLUSION}

The results of this study underline the importance of diabetes education in insulin-treated patients with T2DM. In addition, they demonstrate that perceived hyperglycaemia and higher HbA1c levels are important factors for patient's treatment satisfaction. Healthcare providers should be attentive to patients with a lower health status, frequently perceived hyperglycaemia and higher HbAlc levels to discuss and improve their diabetes treatment satisfaction. Self-management education programmes should incorporate these factors for ongoing support in patients with T2DM. The lack of an association between treatment satisfaction, and insulin regimen or insulin injection frequency is favourable.

Collaborators GUIDANCE study group: M Stone, G Charpentier, K Doggen, 0 Kuss, U Lindblad, C Kellner, J Nolan, A Pazderska, M Trento and V Jörgens.

Contributors AMB and TGTH wrote the manuscript and analysed the data. Data were collected by the GUIDANCE study group. GEHMR and RCV designed the current study, contributed to the discussion, reviewed and edited the manuscript. NPAZ provided statistical advice, contributed to the discussion, reviewed and edited the manuscript. NM and KK reviewed and edited the manuscript.

Funding The original GUIDANCE study was funded by the European Association for the Study of Diabetes from a grant from Merck \& Co. (White House Station, New Jersey, USA). The principal investigator from each of the eight participating countries received financial support from this grant to conduct the study in their country (KK for the UK and GEHMR for the Netherlands). For the current study we did not receive funding.

Competing interests AMB reports an unrestricted grant from Sanofi-Aventis for a study in type 2 diabetes patients on insulin therapy (support of self-management by mHealth), outside the submitted work. RCV reports an unrestricted grant from Sanofi-Aventis for a study in type 2 diabetes patients on insulin therapy (support of self-management by mHealth). Also an unrestricted grant is received from European Foundation for the Study of Diabetes for a study on the long-term effects of a self-management education course for patients with type 2 diabetes. Both outside the submitted work. TGTH, NPAZ and NM have nothing to disclose. KK is 
supported by the National Institute for Health Research Collaboration for Leadership in Applied Health Research and Care, East Midlands (NIHR CIAHRC, EM) and the NIHR Leicesterâ€"Loughborough Diet, Lifestyle and Physical Activity Biomedical Research Unit, which is a partnership between University Hospitals of Leicester NHS Trust, Loughborough University and the University of Leicester, UK (outside the submitted work). GEHMR received an unrestricted research grant from SanofiAventis and fees from Novo Nordisk for consultancy and lecturing, outside the submitted work.

Ethics approval Each country obtained Ethical Committee approval for the original GUIDANCE study.

Provenance and peer review Not commissioned; externally peer reviewed.

Data sharing statement Conditionally: data sharing should be possible in accordance with the European Association for the Study of Diabetes.

Open Access This is an Open Access article distributed in accordance with the Creative Commons Attribution Non Commercial (CC BY-NC 4.0) license, which permits others to distribute, remix, adapt, build upon this work non-commercially, and license their derivative works on different terms, provided the original work is properly cited and the use is non-commercial. See: http://creativecommons.org/ licenses/by-nc/4.0/

(C) Article author(s) (or their employer(s) unless otherwise stated in the text of the article) 2017. All rights reserved. No commercial use is permitted unless otherwise expressly granted.

\section{REFERENCES}

1. Rutten G, De Grauw WJC, Nijpels G, et al. NHG-Standaard Diabetes mellitus type 2 (derde herziening). Huisarts Wet 2013;56:512-25.

2. Kunt T, Snoek FJ. Barriers to insulin initiation and intensification and how to overcome them. Int J Clin Pract 2009;63:6-10.

3. Furler J, O'Neal D, Speight J, et al. Supporting insulin initiation in type 2 diabetes in primary care: results of the Stepping Up pragmatic cluster randomised controlled clinical trial. BMJ 2017;356:j783.

4. Kasteleyn MJ, de Vries L, van Puffelen AL, et al. Diabetes-related distress over the course of illness: results from the Diacourse study. Diabet Med 2015;32:1617-24.

5. Vijan S, Hayward RA, Ronis DL, et al. Brief report: the burden of diabetes therapy: implications for the design of effective patientcentered treatment regimens. J Gen Intern Med 2005;20:479-82.

6. Nicolucci A, Cucinotta D, Squatrito S, et al. Clinical and socioeconomic correlates of quality of life and treatment satisfaction in patients with type 2 diabetes. Nutr Metab Cardiovasc Dis 2009;19:45-53.

7. Bener A, Al-Hamaq AO, Yousafzai MT, et al. Relationship between patient satisfactions with diabetes care and treatment. Niger J Clin Pract 2014;17:218.

8. Biderman A, Noff E, Harris SB, et al. Treatment satisfaction of diabetic patients: what are the contributing factors? Fam Pract 2009;26:102-8.
9. Redekop WK, Koopmanschap MA, Stolk RP, et al. Health-related quality of life and treatment satisfaction in Dutch patients with type 2 diabetes. Diabetes Care 2002;25:458-63.

10. Zyoud Sa'ed H., Al-Jabi SW, Sweileh WM, et al. Relationship of treatment satisfaction to health-related quality of life among Palestinian patients with type 2 diabetes mellitus: Findings from a cross-sectional study. J Clin Trans/ Endocrinol 2015;2:66-71.

11. Depablos-Velasco P, Salguero-Chaves E, Mata-Poyo J, et al. Quality of life and satisfaction with treatment in subjects with type 2 diabetes: results in Spain of the PANORAMA study. Endocrinol Nutr 2014;61:18-26.

12. Narayan KM, Gregg EW, Fagot-Campagna A, et al. Relationship between quality of diabetes care and patient satisfaction. J Natl Med Assoc 2003;95:64-70.

13. Finkel ML. The importance of measuring patient satisfaction. Emp/ Benefits J 1997;22:12-15.

14. Bradley C, Lewis KS. Measures of psychological well-being and treatment satisfaction developed from the responses of people with tablet-treated diabetes. Diabet Med 1990;7:445-51.

15. Ozder A, Sekeroglu M, Eker HH, et al. Quality of life and satisfaction with treatment in subjects with type 2 diabetes: results from primary health care in Turkey. Int J Clin Exp Med 2014;7:5715-22.

16. Stone MA, Charpentier G, Doggen K, et al. Quality of care of people with type 2 diabetes in eight European countries: findings from the Guideline Adherence to Enhance Care (GUIDANCE) study. Diabetes Care 2013;36:2628-38.

17. Bradley C. Diabetes treatment satisfaction questionnaire. Handbook of Psychology and Diabetes, 1994:P 111-32.

18. The Euroqol Group. EuroQol - a new facility for the measurement of health-related quality of life. Health Policy 1990;16:199-208.

19. Hoelzel W, Weykamp C, Jeppsson JO, et al. IFCC reference system for measurement of hemoglobin A1c in human blood and the national standardization schemes in the United States, Japan, and Sweden: a method-comparison study. Clin Chem 2004;50:166-74.

20. Müller N, Frank T, Kloos C, et al. Randomized crossover study to examine the necessity of an injection-to-meal interval in patients with type 2 diabetes and human insulin. Diabetes Care 2013;36:1865-9.

21. Nicolucci A, Maione A, Franciosi M, et al. Quality of life and treatment satisfaction in adults with Type 1 diabetes: a comparison between continuous subcutaneous insulin infusion and multiple daily injections. Diabet Med 2008;25:213-20.

22. Maiorino MI, Bellastella G, Petrizzo M, et al. Treatment satisfaction and glycemic control in young Type 1 diabetic patients in transition from pediatric health care: CSII versus MDI. Endocrine 2014;46:256-62.

23. Haas L, Maryniuk M, Beck J, et al. National standards for diabetes self-management education and support. Diabetes Care 2012;35:2393-401.

24. Ismail-Beigi F, Moghissi E, Tiktin M, et al. Individualizing glycemic targets in type 2 diabetes mellitus: implications of recent clinical trials. Ann Intern Med 2011;154:554-9.

25. Voorham J, Haaijer-Ruskamp FM, Wolffenbuttel BH, et al. Differential effects of comorbidity on antihypertensive and glucoseregulating treatment in diabetes mellitus--a cohort study. PLoS One 2012;7:e38707. 